\title{
Introduction to the special section on urothelial imaging
}

\author{
Lejla Aganovic ${ }^{1}$
}

Published online: 12 September 2019

(c) This is a U.S. Government work and not under copyright protection in the US; foreign copyright protection may apply 2019

This special section in Abdominal Radiology is dedicated to imaging of the urothelium. Leading experts and authorities in the field have contributed articles covering broad range of topics related to the urothelial imaging. The goal of this issue is to provide comprehensive, state-of-the-art articles on all components of the urothelial tract including renal pelvis, ureters, bladder, and urethra. Majority of the articles included in this edition are divided based on an organ-specific or disease-specific approach covering a wide variety of topics ranging from trauma, benign, and malignant tumors to congenital conditions. The issue also highlights some of the recent advances in imaging techniques while providing guidance on how to optimize the existing techniques. Additional articles address the latest advances in genetic profiling of urothelial carcinoma, the current role of imaging, and the radiographic appearance of treatment response and address potential future areas of imaging research.

I am honored to have served as the guest editor for this issue and wish to thank Dr. Daniel Johnson, the Editor-inChief, for this opportunity. I am also extremely grateful to all the contributing authors for their tremendous dedication to this project and their willingness to share their expertise. I am confident that the manuscripts included in this section will serve as a valuable reference resource for practicing radiologists and to all who care for their patients.

Publisher's Note Springer Nature remains neutral with regard to jurisdictional claims in published maps and institutional affiliations.
Lejla Aganovic

laganovic@ucsd.edu

1 Department of Radiology, University of California San Diego, 200 West Arbor Dr, San Diego, CA 92103, USA 